\title{
MACROINVERTEBRADOS BENTÔNICOS COMO BIOINDICADORES DA QUALIDADE DA ÁGUA EM UM TRECHO DO RIO APODI-MOSSORÓ
}

\author{
A. H. S. BARBOSA ${ }^{1 *}$; C. S. P. SILVA ${ }^{1}$; S. E. ARAÚJO ${ }^{1}$; T. B. B. LIMA ${ }^{1}$ e I. M. DANTAS ${ }^{1}$ \\ ${ }^{1}$ Universidade do Estado do Rio Grande do Norte \\ helton_asb@hotmail.com*
}

Artigo submetido em fevereiro/2016 e aceito em setembro/2016

DOI: $10.15628 /$ holos.2016.4183

\begin{abstract}
RESUMO
Este trabalho foi realizado com o intuito avaliar a presença de macroinvertebrados bentônicos como bioindicadores da qualidade da água em um trecho do rio Apodi-Mossoró no município de Governador Dix-Sept Rosado, Rio Grande do Norte. Para isso, foram realizadas coletas em três pontos de um trecho do rio ApodiMossoró. A identificação dos invertebrados foi feita através de estereomicroscópio com o auxílio de bibliografias especializadas. A quantidade de macroinvertebrados foi expressa em número de macroinvertebrados e por metro quadrado de acordo com a ferramenta utilizada. Foram encontrados nos três pontos organismos pertencentes os filos insecta e
\end{abstract}

mollusca, no qual o filo mollusca foi o mais representativo em todos os pontos amostrados, apresentando um total de 17.725 indivíduos por $\mathrm{m}^{2}$ coletados com a draga e 831 indivíduos com o pegador manual. A classe gastropoda foi a que apresentou mais indivíduos em todas as coletas principalmente da família dos Thiarídeos representados pela espécie Melanoide tuberculata, um fato preocupante a saúde pública, tendo em vista que esta espécie é vetor de doenças como a esquistossomose. De modo geral, foram coletados em maior abundância indivíduos resistentes à poluição, sendo um indicativo de que as águas dos pontos amostrados possam estar poluídas e/ou contaminadas.

PALAVRAS-CHAVE: Bioindicador, macroinvertebrados bentônicos, qualidade da água.

\section{BENTHIC MACROINVERTEBRATES AS BIOINDICATORS WATER QUALITY IN A STRETCH OF RIVER APODI-MOSSORÓ}

\begin{abstract}
This work was carried out aiming to evaluate the presence of benthic macroinvertebrates as bioindicators of water quality in a stretch of the river Apodi-Mossoró in the municipality of Governador Dix-Sept Rosado, Rio Grande do Norte. For this, samples were taken at three points of a stretch of the river Apodi-Mossoró. The identification of invertebrates was made through a stereomicroscope with the aid of specialized bibliographies. The quantity of macroinvertebrates was expressed as number of macroinvertebrates and per square meter in accordance with the tool used. Were found in three points bodies belonging to the phyla insecta and Mollusca, in which the Phylum Mollusca was
\end{abstract}

the most representative in all sampled points, presenting a total of 17.725 individuals per $\mathrm{m}^{2}$ collected with the dredger and 831 individuals with grip for the manual. The class gastropoda was the one that presented more individuals in all collections of the family of Thiarídeos mainly represented by the species Melanoide tuberculata, a worrying fact public health, with a view that this species is a vector of diseases such as schistosomiasis. In general, were collected in greater abundance individuals resistant to pollution, being an indication that the waters of the sampled points can be polluted and/or contaminated..

KEYWORDS: Bioindicador, benthic macroinvertebrates, water quality. 


\section{INTRODUÇÃO}

Os macroinvertebrados bentônicos são animais aquáticos de hábito bentônico, isto é, que habitam o fundo de ambientes lênticos e lóticos aderidos a pedras, cascalhos, folhas ou enterrados em sedimentos, lama ou areia. Constituem um dos grupos biológicos mais diversificados e abundantes dos ambientes aquáticos (ZARDO et al., 2013). Além disso, desempenham um papel fundamental na degradação do material alóctone em riachos (SANTOS; RODRIGUES, 2015).

Nesse sentido, a importância da comunidade bentônica para os ecossistemas aquáticos está associada ao fluxo de energia e nutrientes, participando ativamente da decomposição da matéria orgânica e integrando a cadeia alimentar. Além disso, diversas espécies bentônicas favorecem as trocas de materiais entre os sedimentos e a coluna de água por ação mecânica, promovendo o revolvimento dos sedimentos e propiciando a disponibilização de nutrientes (CUNHA; CALIJURI, 2012).

Os impactos ambientais causados pelas ações antrópicas, têm levado a degradação da qualidade da água em diversos corpos hídricos, dificultando a utilização de tal recurso para satisfação até mesmo das necessidades básicas humanas (CARDOSO; NOVAES, 2013). Nesse contexto, os macroinvertebrados bentônicos são amplamente utilizados como bioindicadores de qualidade da água em todo o mundo, devido, as suas características fisiológicas e morfológicas (REMOR et al., 2013) que determinam sua sensibilidade em relação a poluição ou degradação dos ecossistemas aquáticos (ELLER et al., 2009).

O monitoramento biológico ou biomonitoramento pode ser definido como o uso sistemático de respostas biológicas para avaliar mudanças ambientais com o objetivo de utilizar esta informação em um programa de controle de qualidade. Deste modo, um importante componente desse tipo de estudo é o uso de organismos vivos, especialmente aqueles que apresentam sensibilidade ou tolerância a determinadas condições ambientais, com o objetivo de captar aspectos do ambiente e fornecer informações científicas e de gerenciamento úteis (LADSON et al. 1999).

Os organismos aquáticos, principalmente invertebrados, são os que melhor respondem às mudanças das condições ambientais. Ambientes fortemente impactados mostram poucas espécies que, se estiverem bem adaptadas, podem exibir ótimo desenvolvimento e o monitoramento de estações a montante e a jusante da fonte poluidora, pode identificar as consequências ambientais para a qualidade de água e saúde do ecossistema aquático (MATSUMARA-TUNDISI, 1999).

A preferência pela utilização dos macroinvertebrados bentônicos como bioindicadores deve-se aos ciclos de vida longa permitindo uma análise espacial eficiente dos efeitos das perturbações, a facilidade de amostragem com custos relativamente baixos, elevada diversidade taxonômica e de identificação relativamente fácil, organismos sensíveis a diferentes concentrações de poluentes no meio, fornecendo assim, uma ampla faixa de respostas frente a diferentes níveis de contaminação ambiental (NAIME; SPILKI, 2012).

Para Cunha e Calijuri (2013) os atributos que fazem com que os macroinvertebrados bentônicos sejam bons bioindicadores são: 
- Significativa diversidade taxonômica - em função da elevada diversidade de grupos taxonômicos, podem ser encontrados macroinvertebrados bentônicos sensíveis ou tolerantes às atividades humanas, oferecendo um significativo espectro de respostas às alterações ambientais.

- Abundância - esses organismos são relativamente comuns e de ocorrência generalizada na maioria dos sistemas aquáticos.

- Sedentarismo - os macroinvertebrados bentônicos não são capazes de se deslocar por grandes distâncias, o que impede a migração quando as características do meio aquático não Ihes são favoráveis.

- Ciclo de vida - possuem ciclo de vida extenso, o que torna possível sua utilização contínua como bioindicador ao longo do tempo.

- Facilidade de coleta - os macroinvertebrados são facilmente coletados e os principais métodos para avaliação da qualidade da água são o levantamento de alterações na diversidade de espécies encontradas e a análise do nível de perda de espécies sensíveis.

Desta forma, o biomonitoramento baseado na estrutura da comunidade de macroinvertebrados bentônicos é um dos métodos mais eficazes para avaliação da qualidade da água (QUEIROZ; TRIVINHO-STRIXINO; NASCIMENTO, 2000).

Portanto, torna-se de suma importância a coleta, preservação e classificação de macroinvertebrados para identificação da qualidade da água. Assim, o presente artigo objetivou avaliar a presença de macroinvertebrados bentônicos como bioindicadores da qualidade da água em um trecho do rio Apodi-Mossoró no município de Governador Dix-Sept Rosado, Rio Grande do Norte.

\section{MATERIAL E MÉTODO}

O experimento foi realizado em três pontos de um trecho do Rio Apodi-Mossoró, no município de Governador Dix-Sept Rosado (Figura 1). Os pontos de coleta foram previamente selecionados considerando um dos pontos na zona urbana do município (P2), um a jusante (P1) e outro a montante (P3) da zona urbana.

As coletas foram realizadas na região marginal do rio em uma faixa de aproximadamente 1 metro da margem, a uma profundidade máxima de 1 metro. Em cada ponto amostrado foram realizadas 2 coletas, sendo uma com draga Van Veen $\left(33 \mathrm{~cm}^{2}\right)$ e outra com rede entomológica de mão (malha 0,5 mm). Todas as amostras foram coletadas em 27 de junho de 2015 no período de estiagem. Para calcular a quantidade de organismos por metro quadrado, foram contabilizados os organismos e multiplicado por 0,0033 metros, equivalente a capacidade da draga.

Para a coleta dos sedimentos utilizou-se uma draga tipo Van Veen, no qual soltava-se aberta a uma altura de aproximadamente 1 metro, fechava-a e retirava-se da água, os sedimentos eram despejados cuidadosamente na rede entomológica de mão e então lavava-se o material no corpo hídrico até retirar o excesso de sedimentos finos. Em seguida os materiais foram armazenados em potes de plástico identificados e com álcool 70\% para conservação. 
Na coleta utilizando somente a rede entomológica de mão, o procedimento era arrastá-la pelo fundo do corpo hídrico até coletar uma quantidade considerável de sedimentos, esse passava por um processo de lavagem utilizando a água do próprio corpo hídrico, em seguida os sedimentos eram armazenados em potes de plástico com álcool a $70 \%$.

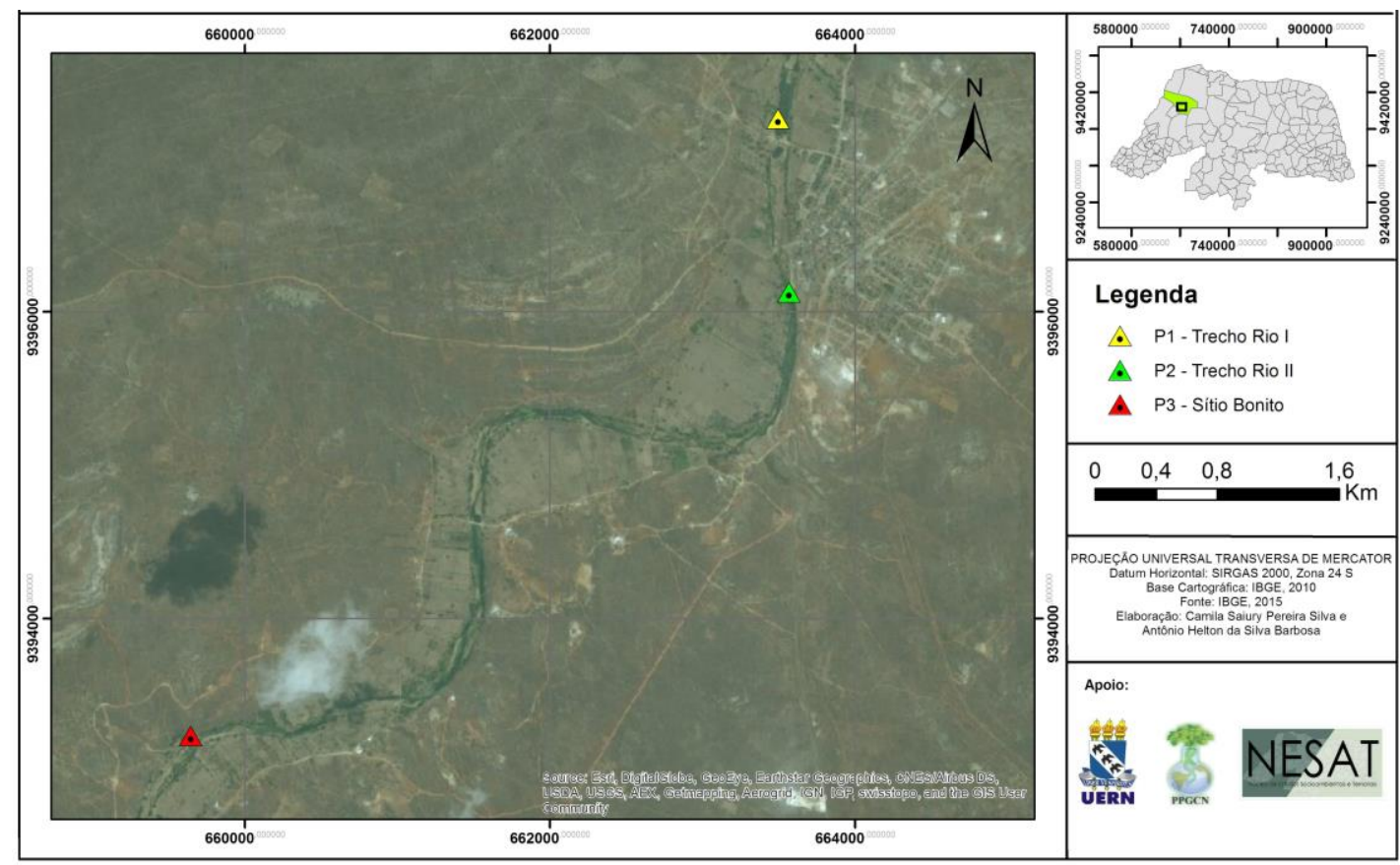

Figura 1: Mapa de localização dos pontos amostrados, município de Governador Dix-Sept Rosado/RN. Fonte: Autores, 2015.

As amostras coletadas foram conduzidas ao Laboratório de biologia da UERN onde foram dispostas separadamente em bandeja transiluminada. Com o auxílio de uma pinça realizou a seleção dos organismos dentre os sedimentos. Os macroinvertebrados bentônicos encontrados foram identificados, pré-classificados e quantificados, em seguida acondicionados novamente em recipientes plásticos contendo álcool a $70 \%$ para preservação das amostras. A identificação foi realizada através de estereomicroscópio com o auxílio de bibliografias especializadas.

\section{RESULTADOS E DISCUSSÃO}

\subsection{Aspectos ambientais}

$\mathrm{O}$ primeiro ponto de coleta foi realizado no P1, localizado a jusante da zona urbana do município, em uma área denominada por populares como Sítio Pedrinha. Situa-se no médio curso do Rio Apodi-Mossoró, o trecho é caracterizado como um ambiente lótico com correnteza fraca e profundidade de aproximadamente $30 \mathrm{~cm}$ de lâmina d'água, com presença de grande quantidade de macrófitas aquáticas (Figuras 2 ) e peixes de pequeno porte. 


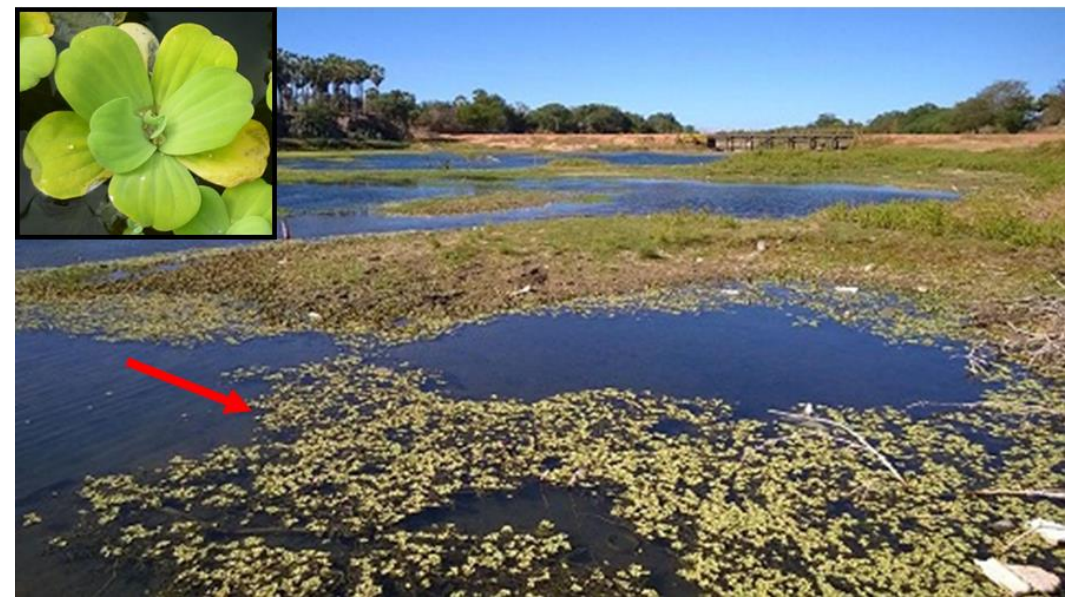

Figura 2: Presença de macrófitas, em destaque alface d’água (Pistia stratiotes), P1. Fonte: Autores, 2015.

A baixa profundidade da água neste local, provavelmente está relacionada ao assoreamento do curso hídrico, possivelmente provocado pelas ações antrópicas ao longo do rio, como desmatamentos e erosões do solo. $O$ assoreamento é a obstrução do corpo d'água pelo acúmulo de substância mineral ou orgânica, que reduz a profundidade e a velocidade de sua correnteza, como consequências, podem ocorrer dificuldades no trafego das embarcações, redução da atividade pesqueira e agravamento do efeito das inundações (PEREIRA, 2012).

Além disso, as margens do curso hídrico apresentaram grande quantidade de ovos de caramujos (gênero Pomacea) presos em pedras (Figura 3), na vegetação aquática e até em resíduos sólidos que estavam dispostos de forma inadequada no local. Também foram observadas aves se alimentando de pequenos peixes e macroinvertebrados bentônicos.

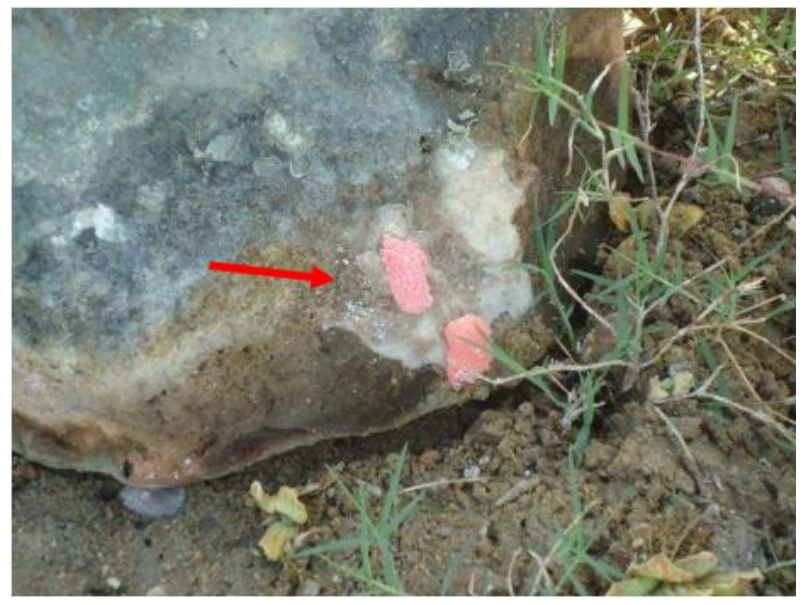

Figura 3: Ovos de caramujos (gênero Pomacea) presos a pedra no, P1. Fonte: Autores, 2015.

$\mathrm{Na}$ área do entorno, também observou-se a presença de vegetação ciliar, erosões no do solo (voçoroca), presença de animais pastando, residências sem esgotamento sanitário, mulheres lavando de roupas no rio (Figura 4a), sinais de dragagem de areia (Figura 4b) e resíduos sólidos espalhados pela margem e no curso hídrico. 


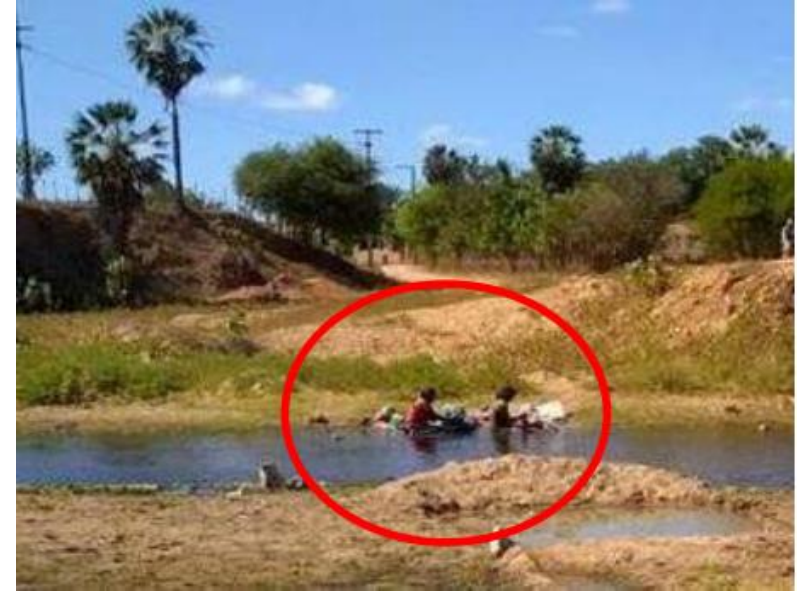

a)

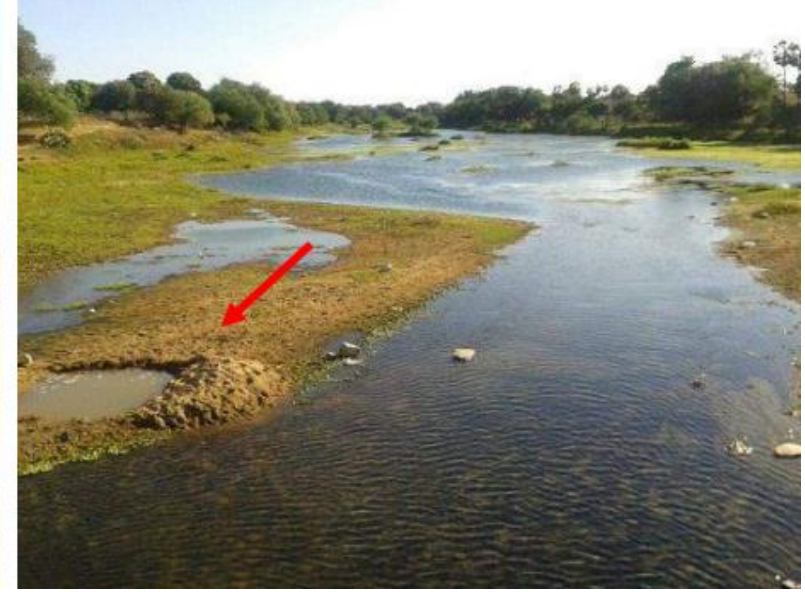

b)

Figura 4: Aspectos ambientais observados no P1 - a) Mulheres lavando roupa no rio; b) Evidência de dragagem. Fonte: Autores, 2015.

O segundo ponto de coleta, denominado P2, está situado na zona urbana do município. $\mathrm{O}$ trecho é caracterizado como um ambiente lótico com correnteza fraca e profundidade de superior a 1 metro de d'água com afloramento da rocha calcária (Formação Jandaíra) na margem do rio. No local, foi observada intensa atividade de dragagem de areia. Essa atividade retira frequentemente os sedimentos do curso hídrico, levando consigo possivelmente os macroinvertebrados bentônicos que habitam o fundo do rio, entretanto, foram observados grandes quantidades gastrópodes como podemos observar na Figura 5. Além disso, havia a presença de macrófitas e larvas de peixes.

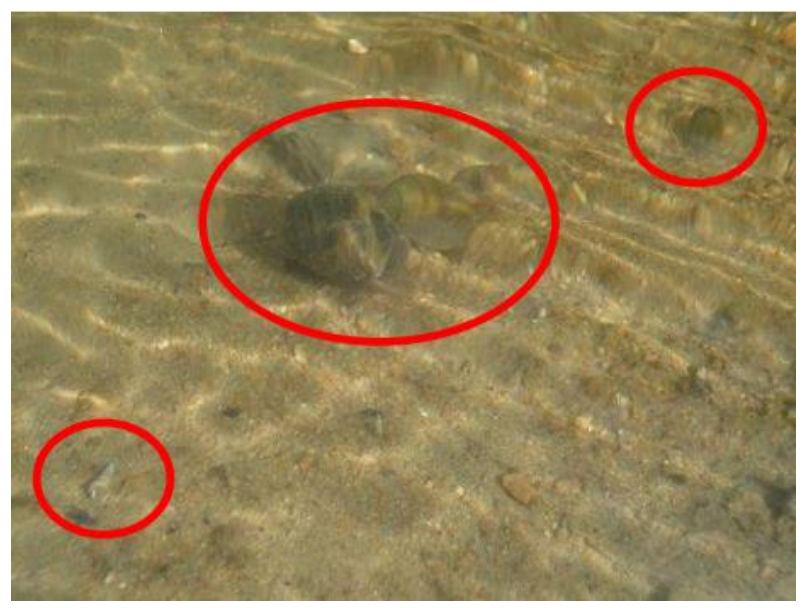

Figura 5: Gastrópodes na margem do trecho do rio Apodi-Mossoró, P2. Fonte: Autores, 2015.

Percebeu-se nesse ponto que a água do rio apresentava odor desagradável, provavelmente originado de efluentes domésticos despejados no curso hídrico. Não foi visualizado despejo de esgotos literalmente nas proximidades, entretanto, havia evidências que as águas cinza são despejadas no rio. Nesse local havia pessoas lavando roupas, prática comum na cidade e caminhão pipa retirando água do local. Além disso, foram visualizados resíduos sólidos dispersos pelo local e animais pastando no entorno, no qual pode provocar contaminação da água por excrementos.

O terceiro ponto de coleta, denominado P3, localizado no Sítio Bonito, na área do Poço feio. O Poço feio situa-se aproximadamente $6 \mathrm{~km}$ da zona urbana do município e é utilizado pela 
população local e por turistas como área de recreação/lazer por possuir uma nascente de água em meio ao afloramento calcário, no qual forma-se uma piscina natural. Além disso, o Poço feio está inserido na área de preservação permanente (APP) do rio Apodi-Mossoró.

Esse ponto é caracterizado como um ambiente lêntico com profundidade de aproximadamente $30 \mathrm{~cm}$ de lâmina d'água, próximo a um paredão de rochas calcária com presença de várias raízes de plantas. Diferentemente dos outros dois pontos, este estava sombreado. $A$ respeito dos aspectos ambientais, foram observados resíduos sólidos no entorno, no qual provavelmente eram oriundos da alimentação dos visitantes. Foram visualizados animais pastando, excrementos, e grande quantidade de matéria orgânica em decomposição (folhas, galhos, raízes e etc.).

3.2 Avaliação da presença dos macroinvertebrados bentônicos como bioindicadoes da qualidade da água.

O Quadro 1 apresenta os resultados obtidos com a coleta, triagem e classificação dos macroinvertebrados bentônicos nos três pontos de coleta.

Quadro 1: Taxonomia dos Macroinvertebrados Bentônicos encontrados nos três pontos coletados.

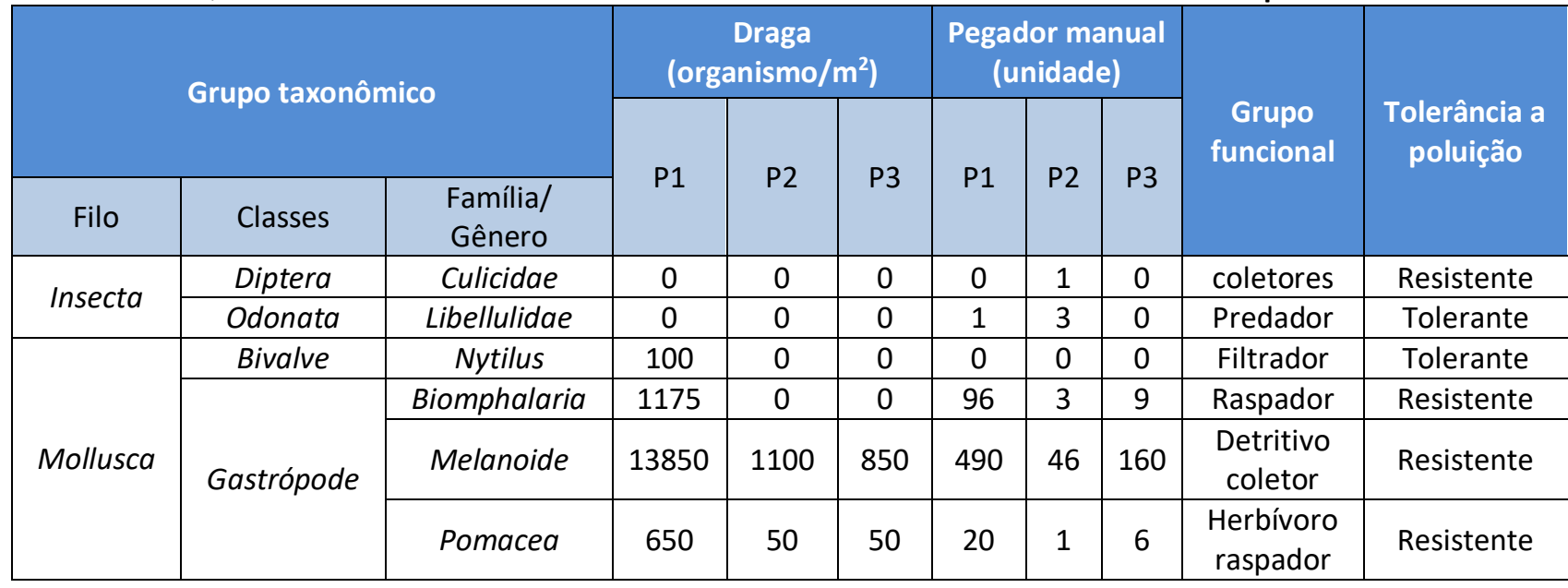

Foram coletados nos três pontos organismos pertencentes os filos Insecta e Mollusca, no qual o filo Mollusca foi o que apresentou maior abundância, sendo este filo o mais representativo em todos os pontos coletados, apresentando um total de 17.725 indivíduos por $\mathrm{m}^{2}$ coletados com a draga e 831 indivíduos com o pegador manual, enquanto o filo Insecta foi coletado apenas 5 indivíduos com o pegador manual. Esses resultados corroboram com Esteves (1998) e Callisto (2000) no qual apontam que uns dos principais grupos de macroinvertebrados aquáticos são os moluscos. De modo geral, foram coletados em maior abundância indivíduos resistentes à poluição, enquanto indivíduos tolerantes foram em menores quantidades. Quanto à cadeia trófica foram coletados predadores, herbívoros raspadores, detritívoros coletores, raspadores e filtradores, sendo que os detritívoros coletores foram mais abundantes.

Em relação aos pontos de coleta, o P1 foi o que apresentou uma maior abundância total de macroinvertebrados bentônicos com 15.775 indivíduos por $\mathrm{m}^{2}$ (draga) e 607 indivíduos (pegador manual), representando $89 \%$ do total de organismos coletados com a draga e $73 \%$ com o pegador manual, enquanto no P2 foram encontrados 1.150 indivíduos por $\mathrm{m}^{2}$ (6\%) e 54 indivíduos com o 
pegador manual (6\%); e no P3 foram 900 indivíduos por $\mathrm{m}^{2}$ (5\%) e 175 indivíduos com o pegador manual, representando $21 \%$ organismos coletados com essa ferramenta. A Figura 6 apresenta as quantidades macroinvertebrados bentônicos nos diferentes pontos de coleta por instrumento utilizado.

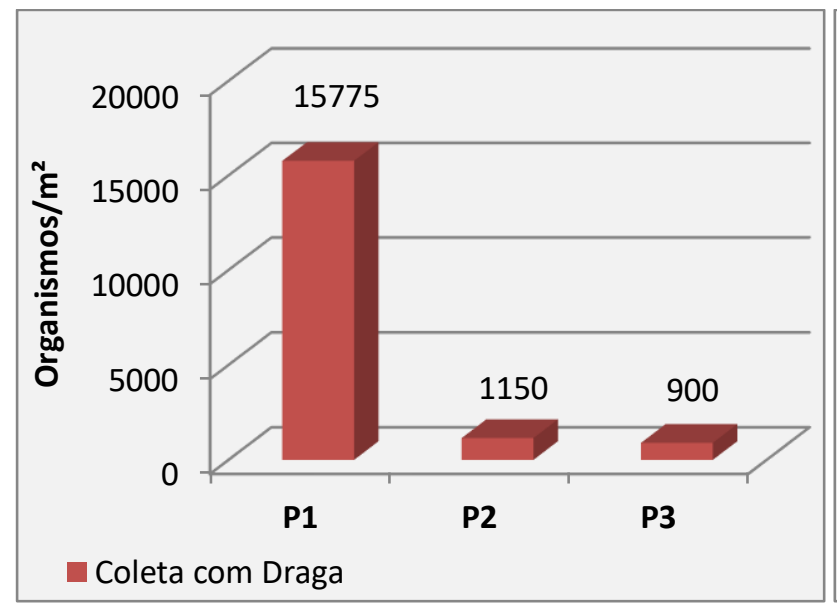

a)

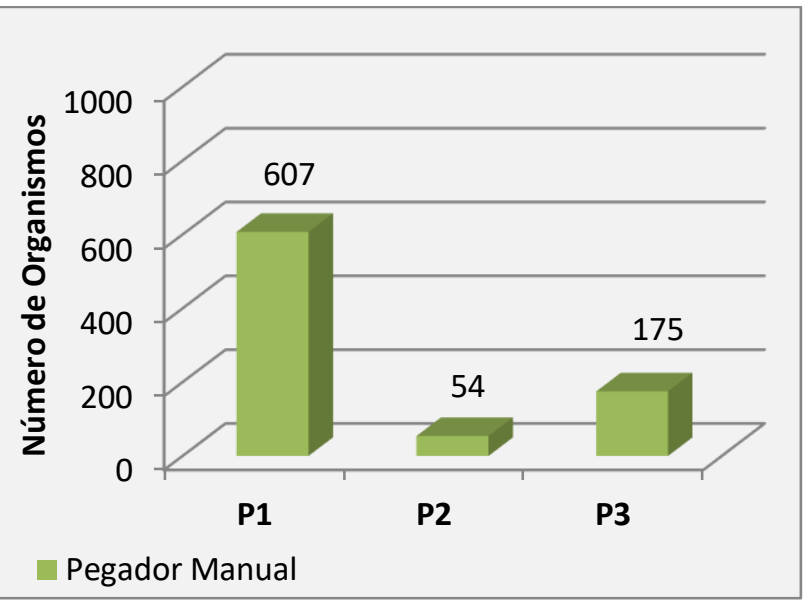

b)

Figura 6: Total de macroivertebrados bentônicos coletados nos três pontos - a) coleta com draga; b) coleta com pegador manual.

Fonte: Autores, 2015.

O Filo Insecta, da família Libellulidae e classe Odonata apresentou o maior número de insetos coletados com o pegador manual (quatro indivíduos). Esses insetos vivem geralmente em margens de rios e lagos que possuem vegetação abundante e águas limpas ou pouco poluídas. Desta forma, cabe salientar que em todos os pontos de coleta foram observadas atividades antrópicas que alteram o ambiente, nos dois trechos do rio Apodi-Mossoró, P1 e P2, percebeu-se, também, indicativos de dragagem, lançamentos de esgotos domésticos, lavagem de roupa, resíduos sólidos, excrementos de animais dentre outros, que podem justificar a baixa presença desses organismos e a abundância do filo Mollusca. Além disso, a coleta foi realizada no período de estiagem, que de certa forma pode ter influenciado na quantidade desses organismos.

Já em relação ao fio Mollusca, a classe Gastrópode do gênero Melanoide foi dominante em todas as coletas. Outros gastrópodes do gênero Biomphalaria e Pomacea foram encontrados em quantidades menores. No entanto, havia a presença em grande quantidade de ovos de caramujos do gênero Pomacea, principalmente, no P1.

Os moluscos do gênero Pomacea, popularmente conhecido como aruás estão largamente distribuídos pelos estados brasileiros e em outros países da América Latina (DORNELLES et al., 2009). Esses organismos estão frequentemente associados com infrapopulações de metazoários, os quais podem ser considerados ectocomensais ou ectoparasitos. Suas desovas são sensíveis a níveis de poluição, consequentemente, pode ser considerado um bioindicador de qualidade de corpos aquáticos em ambientes onde há indícios de sua presença prévia (MELO, 2000; ABÍLIO et al., 2007).

Já a quantidade elevada de gastrópodes do gênero Melanoide identificadas nas amostras corroboram com Dias et al. (2012) no qual realizou um estudo sobre a abundância relativa de macroinvertebrados bentônicos em um trecho do rio Apodi-Mossoró, os autores constataram que 
a espécie Melanoide tuberculata foi dominante em todas as coletas, ainda que, outros gastrópodes como Pomacea lineata e Biomphalaria foram encontrados em menor número. Além disso, os mesmos autores apontam que esses organismos são vetores de enfermidades de veiculação hídrica, podendo causar doenças à população. Segundo Nascimento Filho e Viana (2013) os M. tuberculata caracteriza-se por ser uma espécie não nativa e invasora que consegue se estabelecer nos mais variados ecossistemas aquáticos. Em campo (P1, P2 e P3), contatou-se que a população utiliza os recursos hídricos para diversos fins, desde em lavagem de roupas até para recreação/lazer, esse contato primário (direto) com a água pode transmitir várias doenças para essa população. A maior presença de gastrópodes em todos os pontos coletados, principalmente no $\mathrm{P} 1$, também pode estar relacionada à quantidade de matéria orgânica presente nesse ponto, e ainda por esses moluscos serem resistentes a poluição.

Silva et al. (2006) aponta que a presença em quantidade do filo Mollusca é um indicativo do aumento da quantidade de matéria orgânica na água. Para Abílio (2002), no qual realizou um estudo no açude de Bodogongó na região de Campina Grande na Paraíba, a elevada dominância do $M$. tuberculata indica um ambiente perturbado pelos despejos de esgoto, o que corroboram com as observações feitas em campo. O gênero Melanoide foi o mais abundante em todos os pontos, principalmente, no P1 onde foram encontrados 15.800 indivíduos por $\mathrm{m}^{2}$ (draga) e 696 indivíduos com o pegador manual.

Também é possível visualizar no Quadro 1, que a quantidade de Melanoides decresce entre os pontos, esse resultado pode estar relacionado à cumulatividade dos danos ambientais, no qual nessa perspectiva o P1 seria o mais poluído e o P3 mais conservado mesmo sendo um ambiente lêntico. A qualidade do habitat é um dos fatores mais importantes no sucesso de colonização e estabelecimento das comunidades biológicas em ambientes lênticos ou lóticos. A flora e a fauna presentes em um sistema aquático são também influenciadas pelo ambiente físico do corpo de água como o tipo de substrato (MARQUES et al., 1999).

Em estudo realizado por Oliveira Jr. (2009) em vario trechos de rio Apodi-Mossoró observou-se que esses trechos apresentaram uma fauna dominada pelos moluscos, onde o gastrópode $M$. tuberculata dominou em todos os pontos durante o período de estudo. Lucca et al. (2003) realizaram um estudo nas lagoas Águas Claras (MG) observando que apesar de $M$. tuberculata ser uma espécie invasora e ter grande capacidade de ocupação de habitats, sua distribuição nas lagoas esteve restrita à região litorânea, isto é, em áreas de menor profundidade (menor do que 4 metros) evidenciando que essa espécie se encontra bem estabelecida nesse ponto. Pamplin (1999) registrou valores de densidade que variaram de 15 a 822 indivíduos por $\mathrm{m}^{2}$ na represa de Salto Grande em São Paulo, ele sugere que o desaparecimento de moluscos das famílias Ancyllidae, Planorbiidae e Sphaeridae, anteriormente registradas nessa mesma represa, foi em parte devido à invasão por este molusco invasor, o qual se tornou a única espécie de molusco presente na comunidade bentônica.

Análises de água realizadas recentemente na área de estudo mostraram que nos três pontos amostrados (P1, P2 e P3) as águas foram caracterizadas como duras (acima 200,0 mg/L) e alcalinas, esse resultado está, possivelmente, diretamente relacionado à formação calcária dos ambientes amostrados. Pois, nesse período de estiagem a dissolução da rocha calcária e o pouco volume do corpo hídrico podem contribuir para o aumento do teor de sais na água e, 
consequentemente, o aumento de alcalinidade e da dureza. Abílio (2002) estudando corpos aquáticos do semiárido paraibano constatou uma maior riqueza das espécies de moluscos em ambientes alcalinos.

Muitos organismos são adaptados a sobreviver em ambientes intermitentes através de algumas estratégias morfofisiológico e/ou comportamentais para resistir aos períodos de estiagem. Essas adaptações são de suma importância para as espécies de Zoobentos de região semiáridas, pois permitem a recolonização quando as condições ambientais se tornarem favoráveis novamente. A exemplo destas adaptações podemos citar, o gênero Biomphalaria, gastrópode que produzem ovos de resistência, permitindo sua viabilidade por longos períodos de estiagem (ABÍLIO et al., 2007). Os organismos vivos desse gênero foram o segundo mais abundante no P1.

Barboza, Mucelin e Biesdorf (2012), estudaram pontos de um riacho localizado no município de Medianeira do Estado do Paraná em um ponto do rio que apresentava cobertura vegetal parcial no leito, margens moderadamente estáveis, fundo composto por lama e areia, e a presença de esgoto doméstico tanto na água quanto no sedimento. Neste ponto foi verificada baixa riqueza taxonômica e uma maior densidade de organismos resistentes, pertencentes principalmente ao Filo Annelida e à família Chironomidae. Também foram identificados organismos tolerantes pertencentes ao Filo Mollusca e a Ordem Odonata.

\section{CONSIDERAÇÕES FINAIS}

Os macroinvertebrados bentônicos são utilizados como bioindicadores de qualidade de água devidos suas vantagens em relação a outros métodos, no qual podemos destacar o monitoramento em longo prazo, pouca mobilidade, abundantes, de fácil amostragem e os equipamentos utilizados na coleta são acessíveis. Os dados evidenciaram uma maior presença de moluscos da classe Gastrópode em todos os pontos amostrados, principalmente no ponto 1 (a jusante da zona urbana do município) no qual pode estar relacionado à matéria orgânica presente nesse ponto e a resistência desses organismos a poluição.

De modo geral, foram coletados em maior abundância indivíduos resistentes à poluição, enquanto indivíduos tolerantes apresentaram menores quantidades, esse resultado pode ser um indicativo de que as águas dos pontos amostrados possam estar poluídas e/ou contaminadas.

Deve ser considerado, também, que a coleta ocorreu no período de estiagem, e que para melhores conclusões seria necessário no mínimo outra amostragem no período chuvoso. Desta forma, se faz necessário o desenvolvimento de outras amostragens para ampliar os resultados deste trabalho.

\section{REFERÊNCIAS BIBLIOGRÁFICAS}

1. ABÍLIO, F. J. P. et al. Macroinvertebrados bentônicos como bioindicadores de qualidade ambiental de corpos aquáticos da caatinga. Oecol. Bras., v. 11, p 397-409, 2007.

2. ABÍLIO, F. J. P. Gastrópodes e outros invertebrados do sedimento litorâneo e associados à macrófitas aquáticas, em açudes do semi-árido Paraibano, nordeste do Brasil. Tese de 
Doutorado. Programa de Pós Graduação em Ecologia e Recursos Naturais. Universidade Federal de São Carlos, 179p. 2002.

3. BARBOSA, A. H. S; FERnANDES, S. E. M; LIMA, T. B. B. Protocolo de coleta de macroinvertebrados bentônicos. Disciplina Técnicas de Coleta de Amostras do Curso de PósGraduação em Ciências Naturais da Universidade do Estado do Rio Grande do Norte. Disponibilizado em doc. via e-mail, 2015.

4. BARBOZA, L. G. A.; MUCELIN, C. A.; BIESDORF, D. L. Avaliação da qualidade da água do rio Alegria, Medianeira-PR, por meio de indicadores biológicos. XVII seminário de inorvação cientifica e tecnologica da UTFP. 2012.

5. BROWN, K. M. Resource overlap and competition in pond snails: na experimental analysis. Ecology, v. 63, p. 412-422, 1982.

6. CALLISTO, M. Macroinvertebrados bentônicos. In: Bozelli, R. L.; Esteves, F. A.; Roland, F. Lago Batata: impacto e recuperação de um ecossistema amazônico. Rio de Janeiro: IBUFRJ/SBL, p. 139-152, 2000.

7. CARDOSO, R. DOS S; NOVAES, C. P. Variáveis limnológicas e macroinvertebrados bentônicos como bioindicadores de qualidade da água. Revista Nacional de Gerenciamento de Cidades, v. 01, n. 05, pp. 16-35, 2013.

8. CUNHA, D. G. F; CALIJURI, M. C. Sistemas aquáticos continentais. In: CALIJURI, M. C; CUNHA, D. G. F. (Coord.). Engenharia Ambiental: Conceitos, Tecnologia e Gestão. Campus, 2012. Disponível em <https://books.google.com.br>. Acesso em: 20 de Jul. 2015.

9. DIAS, A. M. et al. Macroinvertebrados bentônicos associados á macrófitas aquáticas em um trecho do rio Mossoró. Revista Verde, v. 7, n. 5, p. 36-39, 2012.

10. DORNELLES, L. E. et al. Aspectos quantitativos das infrapopulacões de metazoários associados à pomacea sp. (mollusca, ampulariidae) da estação de piscicultura da universidade federal de mato grosso do sul, Brasil. Anais do IX Congresso de Ecologia do Brasil, 13 a 17 de Setembro de 2009, São Lourenço-MG.

11. ELLER, A. P. R. et al. Biomonitoramento da Bacia do Rio das Velhas utilizando os Macroinvertebrados Bentônicos Bioindicadores de qualidade de água como ferramenta de avaliação ambiental. 2009 . Disponível em <http://150.164.90.128/assets/files/Biomonitoramento/biomonitoramento-novo.pdf>. Acesso em: 20 de Jul. 2015.

12. ESTEVES, F. A. Fundamentos de Limnologia. Rio de Janeiro: FINEP/INTERCIÊNCIA. p. 575, 1988.

13. LADSON, A. R; et al. Development and testing of an Index of Stream Condition for waterway management in Australia. Freshwater Biology, v. 41, n. 2, p. 453 - 468, 1999.

14. LUCCA, P. G. J. et al. Levantamento de macroinvertebrados bentônicos em viveiros de pisciculturas. XV encontro Latino Americano de iniciação cientifica e XI encontro Latino Americano de pós-graduação-Universidade do Vale do Paraíba, 2003.

15. MARQUES, M. G. S. M., FERREIRA, R. L.; BARBOSA, F. A. R. A comunidade de macroinvertebrados aquáticos e características limnológicas das lagoas Carioca e da Barra, Parque Estadual do Rio Doce, MG. Revista Brasileira de Biologia v. 59, n. 2, p. 203-210, 1999.

16. MATSUMURA-TUNDISI, T. Diversidade de zooplancton em represas do Brasil. In: HENRY, R. Ecologia de reservatórios. São Paulo: FAPESP/FUNDIBIO, 1999. p.41-54. 
17. MELO, L. E. L. 2000. O uso do gastrópode Pomacea lineata (Spix, 1827) como indicador de qualidade de mananciais de água doce do Nordeste do Brasil: Uma proposta metodológica. Resumo (dissertação). Programa regional de Pós - Graduação em Desenvolvimento e Meio Ambiente (PRODEMA)-Universidade Federal da Paraíba.

18. NAIME, R. H; SPILKI, F. R. Preservação ambiental e o caso especial do manejo de resíduos de laboratório: conceitos gerais e aplicados. Universidade Feevale. Novo Hamburgo, Rio grande do Sul, Brasil, 2012.

19. NASCIMENTO FILHO, S. L. DO; VIANA, G. F. S. Macroinvertebrados bentônicos como ferramenta para avaliação da qualidade da água (sertão de Pernambuco, Brasil). XIII JORNADA DE ENSINO, PESQUISA E EXTENSÃO - JEPEX 2013. UFRPE: Recife, 2013.

20. PAMPLIN, P. A. Z. Avaliação da Qualidade Ambiental da Represa de Americana (SP) com Ênfase no Estudo da Comunidade de Macroinvertebrados Bentônicos e Parâmetros Ecotoxicológicos. São Carlos (SP). Dissertação (Mestrado). Escola de Engenharia de São Carlos, Universidade de São Paulo, São Carlos, 111p. 1999.

21. QUEIROZ, J. F.; TRIVINHO-STRIXINO, S.; NASCIMENTO, V. M. C. Organismos bentônicos bioindicadores da qualidade das águas da Bacia do Médio São Francisco. Jaguariúna: EMBRAPA Meio Ambiente, 2000.

22. REMOR, M. B. et al. Qualidade da água do Rio das Pedras utilizando macroinvertebrados bentônicos como bioindicadores. Revista Cascavel, v.6, n.2, p.97-111, 2013.

23. SANTOS, I. G. A. dos; RODRIGUES, G. G. Colonização de macroinvertebrados bentônicos em detritos foliares em um riacho de primeira ordem na Floresta Atlântica do nordeste brasileiro. Iheringia, Série Zoologia, Porto Alegre, 105(1):84-93, 2015.

24. SILVA, P. B. et al. Aspectos físicoquímicos e biológicos relacionados à ocorrência de Biomphalaria glabrata em focos litorâneos da esquistossomose em Pernambuco. Química Nova, v. 29, n. 5, p. 901-906. 2006.

25. ZARDO, D. C. et al. Variação espaço-temporal naabundância de ordens e famílias de macroinvertebrados bentônicos registrados em área de nascente, Campo Verde-MT. REVISTA UNIARA, v.16, n.1, 2013. 